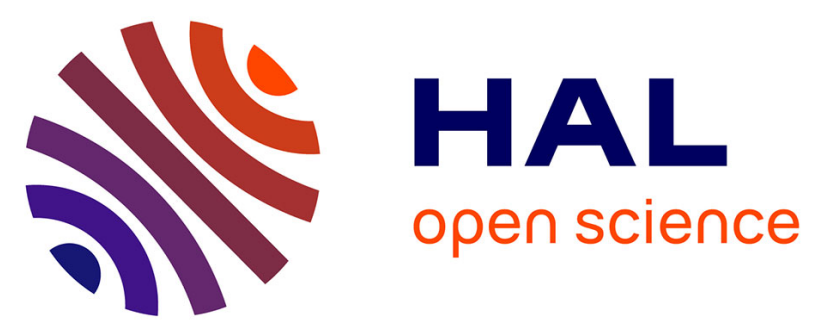

\title{
High-resolution mass spectrometry for future space missions: Comparative analysis of complex organic matter with LAb-CosmOrbitrap and laser desorption/ionization Fourier transform ion cyclotron resonance
}

Laura Selliez, Julien Maillard, Barnabe Cherville, Thomas Gautier, Laurent Thirkell, Bertrand Gaubicher, Isabelle Schmitz-Afonso, Carlos Afonso, Christelle Briois, Nathalie Carrasco

\section{To cite this version:}

Laura Selliez, Julien Maillard, Barnabe Cherville, Thomas Gautier, Laurent Thirkell, et al.. Highresolution mass spectrometry for future space missions: Comparative analysis of complex organic matter with LAb-CosmOrbitrap and laser desorption/ionization Fourier transform ion cyclotron resonance. Rapid Communications in Mass Spectrometry, 2020, 34 (10), pp.e8645. 10.1002/rcm.8645 . insu-02343359

\section{HAL Id: insu-02343359}

https://hal-insu.archives-ouvertes.fr/insu-02343359

Submitted on 10 Dec 2019

HAL is a multi-disciplinary open access archive for the deposit and dissemination of scientific research documents, whether they are published or not. The documents may come from teaching and research institutions in France or abroad, or from public or private research centers.
L'archive ouverte pluridisciplinaire HAL, est destinée au dépôt et à la diffusion de documents scientifiques de niveau recherche, publiés ou non, émanant des établissements d'enseignement et de recherche français ou étrangers, des laboratoires publics ou privés. 
Selliez L. (Orcid ID: 0000-0003-1291-606X)

Gautier T. (Orcid ID: 0000-0002-9794-5056)

Afonso C. (Orcid ID: 0000-0002-2406-5664)

\section{High resolution mass spectrometry for future space missions:} comparative analysis of complex organic matter with LAb-

\section{CosmOrbitrap and LDI-FTICR}

L. Selliez ${ }^{1,2}$, J. Maillard ${ }^{2,3}$, B. Cherville ${ }^{1}$, T. Gautier ${ }^{2}$, L. Thirkell ${ }^{1}$, B. Gaubicher ${ }^{1}$, I. SchmitzAfonso $^{3}$, C. Afonso ${ }^{3}$, C. Briois ${ }^{1}$, N. Carrasco ${ }^{2}$

1- Laboratoire de Physique et Chimie de l'Environnement et de l'Espace (LPC2E), Orléans, FR

2- Laboratoire Atmosphères, Milieux et Observations Spatiales (LATMOS), Guyancourt, FR

3- Université de Rouen, Laboratoire COBRA UMR 6014 \& FR 3038, IRCOF, 1 rue Tesnière 76821 Mont-Saint-Aignan Cedex, FR

This article has been accepted for publication and undergone full peer review but has not been through the copyediting, typesetting, pagination and proofreading process which may lead to differences between this version and the Version of Record. Please cite this article as doi: $10.1002 / \mathrm{rcm} .8645$ 


\section{Abstract}

(RATIONALE) Mass spectrometers are regularly boarded on spacecraft for the exploration of the Solar System. A better understanding of the origin, distribution and evolution of organic matter and its relationships with inorganic matter in different extra-terrestrial environments requires the development of innovative space tools, described as Ultra High Resolution Mass Spectrometry (UHRMS) instruments.

(METHODS) Analyses of a complex organic material simulating extraterrestrial matter (Titan's tholins) are performed with a homemade space-designed Orbitrap ${ }^{\mathrm{TM}}$ equipped with a laser ablation ionization source at $266 \mathrm{~nm}$ : the LAb-CosmOrbitrap. Mass spectra are obtained using only one laser shot and transient duration of $838 \mathrm{~ms}$. A comparison is made on the same sample with a laboratory benchmark mass spectrometer: a Fourier Transform Ion Cyclotron Resonance equipped with a laser desorption ionization at $355 \mathrm{~nm}$ (LDI-FTICR) allowing accumulation of 20,000 laser shots.

(RESULTS) Mass spectra and attributions of molecular formulae based on the peaks detected by both techniques show significant similarities. Detection and identification of the same species are validated. The formation of clusters ions with the LAb-CosmOrbitrap is also presented. This specific feature brings informative and unusual indirect detections about the chemical compounds constituting Titan's tholins. In particular, the detection of $\mathrm{HCN}$ confirms previous results obtained with laboratory Electrospray lonization (ESI)-UHRMS studies about the understanding of polymeric patterns for the formation of tholins.

(CONCLUSION) Capabilities of the LAb-CosmOrbitrap to decipher complex organic mixtures using single laser shot and a short transient are highlighted. In agreement with results provided by a commercial FTICR instrument in the laboratory, we demonstrate in this work the relevance of a space laser-CosmOrbitrap instrument for the future planetary exploration.

This article is protected by copyright. All rights reserved. 


\section{1) Introduction}

Since the boarding of the first space mass spectrometers (MS) on a planetary exploration mission in the 1970s, these instruments have been used to decipher the chemical composition of extraterrestrial bodies such as our closest neighbors Venus and Mars, the outer planets and their moons but also more Solar System primitive objects, as comets and asteroids. In some environments, such as the atmosphere of Titan, the organic matter detected was found to be extremely complex. The CassiniHuygens mission explored the Saturnian environment from 2004 to 2017 using amongst other instruments two quadrupole MS: the lon and Neutral Mass Spectrometer, INMS, aboard Cassini; and the Gas-Chromatograph Mass Spectrometer, GCMS, aboard the Huygens descent module. The interpretation of chemical analysis performed by these instruments was widely reduced due to their poor resolution and the high molecular complexity of the analyzed material resulting in extremely congested mass spectra with a low resolution. For instance, for INMS (Ion Neutral Mass Spectrometer), the identification of a part of the complex organic matter was not direct due to the mass resolution achieved by the instrument ( 100 at $\mathrm{m} / \mathrm{z} 100)$. Using modelling inversion, the team was able to propose possible attributions for a number of peaks in INMS data, up to $m / z<100$. However, the mass resolution of the Cassini-Huygens instruments (INMS, Gas-Chromatograph-MS GCMS and CAssini Plasma Spectrometer CAPS) did not enable to directly decipher the composition of the complex organic matter. For the GCMS instrument, while tens of peaks are visible in the acquired mass spectra (Niemann et al., 2010), only a handful of molecule have been identified so far in it. Deep analytical improvements of new space mass spectrometers are thus needed, in terms of mass resolving power and mass accuracy. Low mass resolving powers $(<1,000)$ from previous space missions have been increased up to 9,000 in more recent space mission (here the value is given for the Double Focusing Magnetic Mass Spectrometer-Rosetta Orbiter Spectrometer for Ion and Neutral Analysis instrument from the Rosetta mission, at $\mathrm{m} / \mathrm{z} 28$, as referenced in Balsiger et al., 2007). In the laboratory, they have been increased to ultra-high ones, higher than 100,000 (Denisov et al., 2012; Nikolaev et al., 2011; Smith et al., 2018). These enhancements, adapted to space MS, will allow a deeper understanding of the extraterrestrial material detected.

The Orbitrap ${ }^{\mathrm{TM}}$ technology (Makarov, 2000; Perry et al., 2008) has been identified as a promising technique in the development of the new generation of space MS. A space-qualified version of the Orbitrap mass analyzer and its peripheral elements, called CosmOrbitrap, is currently under TRL (Technology Readiness Level, i.e. the advancement of the instrument development toward a flight able one) development (Briois et al., 2016). The goal is to reach a mass resolution of a minima 50,000 (Full Width at Half Maximum) at $\mathrm{m} / \mathrm{z} 56$ under ultra-high vacuum conditions up to $10^{-9} \mathrm{mbar}$ in the analyzer chamber. A simplified test-bench in the laboratory directly couples the CosmOrbitrap with a 
Nd-YAG laser at $266 \mathrm{~nm}$ (the LAb-CosmOrbitrap, standing for Laser Ablation CosmOrbitrap). As the instrumental configuration "laser-CosmOrbitrap" is highly considered for a space application (Arevalo Jr et al., 2018), the laboratory prototype has been designed as proof-of-concept, to challenge the performances of a future simple and compact spaceflight HRMS (High Resolution Mass Spectrometry)CosmOrbitrap based instrument.

In the laboratory, highly complex organic matter, mimicking those of Titan's atmosphere, has been synthesized by diverse experiments (Berry et al., 2019; Coll et al., 1999; Gautier et al., 2017; Hörst et al., 2018; Sciamma-O'Brien et al., 2017, 2014; Szopa et al., 2006). This material, named Titan's tholins, is an analogue of the photochemical smog surrounding Titan, well-known for its chemical complexity. A wide variety of organic compounds is thus produced and the whole forms a complex organic mixture. They are considered as primary interest in planetary sciences and exobiology. They have been extensively studied using UHRMS laboratory techniques such as the ESI (Electrospray lonization)Orbitrap $^{\mathrm{TM}}$ and ESI/LDI-FTICR (Laser Desorption Ionization - Fourier Transform Ion Cyclotron Resonance) commercial instruments. Results published in the Gautier et al., 2014; Pernot et al., 2010; and Somogyi et al., 2005 showed a polymeric material, with a highly complex chemical composition and a large number of chemical functionalities specific to nitrogen-rich species such as amino and nitrile compounds. As high analytical performances are now required for mass spectrometers selected on new space missions, Titan's tholins are complex-enough organic standards for testing the capabilities, and thus demonstrating the relevance, of future space UHRMS instruments. Studying Titan's tholins with the LAb-CosmOrbitrap enables to estimate (i) its capabilities to analyze a highly complex organic material, (ii) the chemical analysis allowed by these analytical performances and (iii) its relevance as a future space mass spectrometer dedicated to the study of Titan and other organicrich environments in the Solar System.

In terms of analytical performances, one benchmark MS technique in laboratory is based on FTICR. Indeed, mass resolving powers higher than $20,000,000$ obtained at nominal $\mathrm{m} / \mathrm{z}$ of 608 , i.e. on reserpine (Nikolaev et al., 2011; Smith et al., 2018) are, to this day, unmatched performances. A comparative study is presented here, between the LAb-CosmOrbitrap and a 12 Tesla FTICR. The FTICR is equipped with a LDI source. A laser ionization is thus performed, in both cases, on the same solid sample. Without any specific sample preparation, both techniques provide the analysis of the global material, and not only the soluble fraction as it is usual with the electrospray ionization technique. Using LDI-FTICR, Maillard et al., 2018 have demonstrated major differences in results obtained on the bulk tholins sample and the soluble fraction, in terms of chemical composition. It is thus consistent to compare results between LAb-CosmOrbitrap and LDI-FTICR, both studying the global material of Titan's tholins. Mass spectra obtained using these two MS techniques and molecular attributions

This article is protected by copyright. All rights reserved. 
inferred have been compared. This comparison aims at supporting the potential of the LAbCosmOrbitrap as a potential future simple and compact space UHRMS instrument.

2) Material and methods

\subsection{Synthesis of the complex organic compound studied}

The samples chosen are solid spherical grains with a mean diameter of about $300 \mathrm{~nm}$ and made of nitrogen-rich organic molecules (Hadamcik et al., 2009; Sciamma-O’Brien et al., 2010).

Tholins were synthesized in the radio-frequency plasma reactor called PAMPRE at LATMOS (Szopa et al., 2006) at room temperature. A gas mixture containing $5 \%$ of methane and $95 \%$ of nitrogen flowed into the reactor with a $55 \mathrm{sccm}$ (standard cubic centimeter per minute) total gas influx, leading to a total pressure of 0.9 mbar. A $30 \mathrm{~W}$ radio-frequency plasma discharge produced the reactive molecules leading to the formation of solid grains in the volume of the plasma box with limited wall effects. A few hundred mg of sample were collected in vials after several days of running experiment. We note that some oxidative processes occur on the surface of tholins and probably during ionization. This process is minor and occurs only at the surface of the sample, affecting $3 \%$ of the material (Carrasco et al., 2016a; Fleury et al., 2014). We were nonetheless careful not to over interpret this contamination, and as such we limited our study to molecules without oxygen atoms. These correspond to molecules which have not been altered by the oxidation and a representative of the pristine sample. This was possible thanks to the very good accuracy of measurements of each instrument, allowing the separation of oxygenated species that have lower mass defects than nonoxidized ones.

\subsection{Simple sample preparation}

Tholins were analyzed with LAb-CosmOrbitrap and LDI-FTICR. Both techniques allow a basic sample preparation and introduction in the ionization chamber. No chemical preparation of tholins was done prior to the analysis. This simple deposit of the sample aims at mimicking an in situ study, as it would be done during a space mission. Collecting and bringing samples in front of the ionization system, with a space mass spectrometer, are key parameters for space exploration. In our study case, we assume the sample to be collected and a thin layer to be deposited onto one metallic sample-holder. Specifications of the two set-ups are classified in the Table 1. The first part of this table is related to the sample.

This article is protected by copyright. All rights reserved. 
In the case of the LDI-FTICR set-up, the sample holder is a commercial stainless steel MALDI plate. The sample is deposited using a solvent-free method, following a previously published procedure (Barrère et al., 2012). For the LAb-CosmOrbitrap laboratory prototype, the holder is a homemade circular indium sample-holder ( $7 \mathrm{~mm}$ diameter) on which tholins are pressed and embedded onto the surface (Figure 1). For both techniques, the sample thickness is not tightly controlled but is estimated to be less than $100 \mu \mathrm{m}$.

\subsection{Ultra-High Resolution Mass Spectrometry (UHRMS) techniques used for the study}

\subsubsection{The LAb-CosmOrbitrap laboratory prototype}

The LAb-CosmOrbitrap is a simpler instrumental configuration than the one commercialized by Thermo Fisher Scientific (Bremen, Germany). No quadrupole, no linear trap nor C-trap are used in front of the Orbitrap cell. The Orbitrap cell is directly coupled with a laser ablation ionization source, with an Einzel lens to focalize the ions packet inside the analytical cell, as the C-trap would do in the commercial instrument. Specifications of the ionization source are summarized in the second part of the Table 1. The Nd-YAGx4 laser emitting at $266 \mathrm{~nm}$ (Brilliant model, Quantel corporation) generates a 4 ns pulse. The energy reaching the sample can vary from 30 to $750 \mu \mathrm{J}$, thanks to optics located between the laser output and the sample. Calculations give a fluence ranging from 2.9 to $12 \mathrm{~J} / \mathrm{cm}^{2}$, indicating an ablation/desorption transition and pure ablation laser regimes. The CosmOrbitrap, as it has been used for these experiments, is currently at TRL 3 , which means this is a laboratory prototype used as proof-of-concept, demonstrated analytically and experimentally. We note that the ionization source is not included in the TRL development. One mass spectrum was obtained at each laser shot. The signal transient was composed of 4,194,304 points recorded with a sampling frequency of $5 \mathrm{MHz}$ (Alyxan software). Voltages were set to detect positive ions. A Hann window then a Fast Fourier Transform (FFT) were applied on the full $838 \mathrm{~ms}$ signal transient. Ultra-vacuum is needed with about $10^{-9} \mathrm{mbar}$ and $10^{-8} \mathrm{mbar}$ respectively measured in the mass analyzer and the ionization chambers. For the molecular formula attribution, the two most intense peaks of each nominal mass of the mass spectrum with a signal-to-noise ratio greater than 5 were selected. The molecular formula attributed to each peak selected was the $\mathrm{C}_{x} \mathrm{~N}_{y} \mathrm{H}_{z}$ formula with the closest mass. The formula was considered acceptable if the resulting mass accuracy is lower than $2 \mathrm{ppm}$. Constraints applied for the molecular formula attribution were at most 30 hydrogen atoms, 20 carbon atoms and 20 nitrogen atoms. Even and odd electron configurations were considered.

This article is protected by copyright. All rights reserved. 
With the same prototype configuration (TRL 3), analyses on pure organics and prebiotic compounds have demonstrated mass resolving power (FWHM) up to 70,000 at $\mathrm{m} / \mathrm{z} 430$ and mass accuracy better than 3 ppm (Arevalo Jr et al., 2018; Selliez et al., 2019). A full description of the set-up used in this work can also be found in these papers.

\subsubsection{LDI-FTICR instrumental set-up}

A FTICR (Solarix XR, Bruker Daltonics, Bremen, Germany) equipped with a 12 Tesla superconducting magnet and a laser desorption ionization source was used in this comparative study. The laser is a NdYAGX3 emitting at $355 \mathrm{~nm}$ with a shot frequency of 1,000 Hz. Experimental conditions were similar to those described in Maillard et al., 2018. Mass spectra were obtained using the broadband mode from $\mathrm{m} / \mathrm{z} 98$ to $\mathrm{m} / \mathrm{z} 1,200$ with the sum of 500 scans in positive ion mode. The analogue signal was amplified and digitalized with 8 million points resulting in the recording of transient of about $2.2 \mathrm{~s}$ which was transformed into the corresponding frequency domain by Fourier transform (one zero fill and halfsine apodization). Under these conditions a mass resolution of 600,000 at $\mathrm{m} / \mathrm{z} 430$ was obtained. Ionization parameters were set as follows: deflector plate at $210 \mathrm{~V}$, plate offset at $100 \mathrm{~V}$, laser power at $19 \%$ leading to an output energy of $0.43 \mu \mathrm{J}$ and a "small" laser focus. One scan represents 40 laser shots. Funnel 1 was set at $150 \mathrm{~V}$ and skimmer 1 at $25 \mathrm{~V}$. Pressures of $10^{-3} \mathrm{mbar}$ in the ionization chamber, $10^{-6}$ mbar through ions optics then $3.10^{-10} \mathrm{mbar}$ inside the ICR cell were measured. Molecular formulae were attributed after a peak picking with a signal to noise of 5 using Data Analysis 4.4. Following parameters were set to assign formula: $\mathrm{C}_{0-x} \mathrm{H}_{0-\gamma} \mathrm{N}_{0-z}$, with a maximum number of nitrogen atoms sets to 30 , and even and odd electron configurations with a tolerance of $0.5 \mathrm{ppm}$.

Both instrumental configurations, LAb-CosmOrbitrap and LDI-FTICR, allow the analysis of solid Titan's tholins, leading to the study of the total fraction of the sample. Major differences are still observed in the two set-ups. On one hand, the LAb-CosmOrbitrap is a non-commercial instrumental configuration developed to be a space HRMS, with only one single laser shot, at $266 \mathrm{~nm}$. lonization is performed in a transitional regime between ablation and desorption, with a fluence about $2 \mathrm{~J} / \mathrm{cm}^{2}$. In addition the source pressure is of $10^{-6} \mathrm{mbar}$ in LAb-CosmOrbitrap and $10^{-3} \mathrm{mbar}$ in the FTICR (O'Connor et al., 2002). Higher pressure yields to collisional cooling. A higher extent of fragmentation is thus expected as well as clustering and ion recombination with the LAb-CosmOrbitrap. A short transient duration of $838 \mathrm{~ms}$ leads to one mass spectrum of 4 million points. On the other hand, the LDI-FTICR is a commercial instrument accumulating 500 consecutives FID (Free Induction Decay), each one obtained with 40 laser shots. A pure laser desorption regime is observed. Heavy ions are suspected to be formed and 
detected, due to this softer ionization (in comparison to the LAb-CosmOrbitrap one). The transient duration is about $2.2 \mathrm{~s}$.

3) Results

\subsection{Global comparison between LAb-CosmOrbitrap and LDI-FTICR mass spectra}

We compare mass spectra obtained with both techniques in the $m / z$ range 8 to 600 (Figure 2). At the top, blue mass spectrum corresponds to LAb-CosmOrbitrap data while at the bottom red mass spectrum (in reverse scale) corresponds to LDI-FTICR data. This global comparison is separated in three distinct zones named $\mathrm{A}, \mathrm{B}$ and $\mathrm{C}$.

Zone A corresponds to the lowest masses, with $m / z<100$. Zone $B$ involves intermediate masses, 100 $<m / z<200$. Zone $C$ corresponds to the highest masses, with $m / z>200$.

Zone $A$ is only constituted by the contribution of the LAb-CosmOrbitrap data. The absence of peak detection in the $m / z$ range 0 to 100 , with LDI-FTICR technique, is due to an instrumental constraint of the set-up. Most of the commercial MS techniques used for the Titan's tholins analyses allows data acquisition starting at a $\mathrm{m} / \mathrm{z}$ rather high (e.g. $\mathrm{m} / \mathrm{z}>50$ ). In the case of FTICR, starting detection at lower $\mathrm{m} / \mathrm{z}$ requires a higher sampling frequency (due to the Nyquist Shannon criteria), a shorter transient and so, a lower resolution at higher mass. In this case, the choice of resolving higher masses was done. In addition, RF ion optics of the FTICR that transport ion from the high-pressure source region to the FTICR analyzer are not optimized for transmission of low $\mathrm{m} / \mathrm{z}$ ions (Le Vot et al., 2011; Page et al., 2006). The contrary is observed with the LAb-CosmOrbitrap, with low mass detections starting at $m / z$ 8 , with high mass resolution. These uncommon detections at low masses allow the study of a mass range unexplored so far using other commercial MS instruments but induce also some restrictions at higher masses. The observation of positive ions at $m / z<100$ is also confirmed by the detection of cluster ions and will be detailed in the section 3.3.

In zone $B$, both mass spectra show peaks organized in a polymeric pattern, specific to the complex organics studied (i.e. Titan's tholins). We observe (i) the end of the polymeric pattern detected with LAb-CosmOrbitrap and (ii) the beginning of the signal recorded by LDI-FTICR. It is the best zone for the comparison of results obtained in both techniques.

Unlike zone A, the contribution of LDI-FTCIR data is dominant in zone $C$. The maximum of the polymeric pattern is observed around $m / z 250$, then it decreases down to $m / z 600$. As flat signal (noise level) is 
recorded in the LAb-CosmOrbitrap mass spectrum at $m / z>200$, this range will not be further analyzed in this study but will be discussed in the perspectives.

Focusing on LAb-CosmOrbitrap data obtained with the instrumental parameters referenced in Table 1 , peaks are mainly located on the $m / z$ range 20 to 200 . In this $m / z$ range, three peaks are detected at higher intensities and outside of the window studied (their intensities are reported on the figure). One of them is identified as the indium positive ion $\left({ }^{115} \mathrm{In}^{+}\right)$at $\mathrm{m} / \mathrm{z} 114.903$ (used as mass calibrant). Others are located at $m / z 43.0290$ and 60.0556 and will be studied in the following sections.

\subsection{Comparison of LAb-CosmOrbitrap and LDI-FTICR spectra in zone B}

This section will exclusively focus on the zone B identified on Figure 2. Three zoom on this mass window have been extracted (Figure 3). A first window (top) allows to visualize the whole zone B, on the $m / z$ range 100 to 200 , including detail of each polymeric pattern. Two other mass windows present $\mathrm{m} / \mathrm{z}$ ranges more and more focused on one exclusive nominal mass: $\mathrm{m} / \mathrm{z} 130$ to 155 (middle) and $\mathrm{m} / \mathrm{z}$ 138.0 to 138.2 (bottom).

Waves composing the polymeric pattern are observed, in both cases (LAb-CosmOrbitrap and LDIFTICR), at the same location on the $x$-axis. This is particularly well-observed in the top mass window. The two other mass windows confirm, in addition to the same location of the waves, the same location of each peak inside of these waves. Visually, the LAb-CosmOrbitrap and LDI-FTICR mass spectra are consistent and seem to show the detection of the same species.

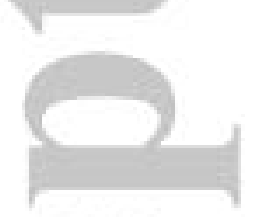

Looking at a specific $m / z$ value, the peak at $m / z 138.077433$ is detected with a mass resolving power of 1,551,160 in the LDI-FTICR mass spectrum. In the LAb-CosmOrbitrap mass spectrum, the same peak is detected at $m / z 138.0771$ with a mass resolving power of 118,778 . We remind here that this study aims at showing results obtained with the LAb-CosmOrbitrap, a simple and compact instrumental configuration (with a D30 cell) developed for space. This is not a commercial Orbitrap, as no C-trap helps to the focalization and accumulation of ions and the transient duration is shorter than the LDIFTICR instrumental configuration used for the comparison. It is thus expected to get mass resolving power lower with the LAb-CosmOrbitrap than with the LDI-FTICR, but the question is to know if the analytical performances of this homemade space-designed Orbitrap are high-enough to allow the peak attribution and species identification unambiguously.

This article is protected by copyright. All rights reserved. 
To answer this question, the Table 2 sets out molecular formulae attributed to peaks similarly detected, for both techniques, in the $\mathrm{m} / \mathrm{z}$ range 133 to 152 . The first and second columns of the table report the theoretical $\mathrm{m} / \mathrm{z}$ of positive ions detected in the mass range and the corresponding molecular formula. Then the table is separated in two main columns: the first one dedicated to the LAb-CosmOrbitrap results and the second one to LDI-FTICR. Each of them is composed of two columns: the experimental $\mathrm{m} / \mathrm{z}$ value of positive ions detected within the precision of the technique considered ( 4 digits for the LAb-CosmOrbitrap values and 6 digits for the LDI-FTICR ones) and the mass accuracy (in ppm). In the 132-152 $\mathrm{m} / \mathrm{z}$ range, 26 molecular formulae have been attributed based on the LAbCosmOrbitrap mass spectrum and 38 based on the LDI-FTICR mass spectrum. The mass resolving power of each technique allows the detection of more than one ion for each nominal mass. For each ion, an attribution was done. For the $m / z$ range studied in this section, 21 ions were detected in common in LAb-CosmOrbitrap and LDI-FTICR mass spectra (in bold in the Table 2).

The global table, including similar detections and discrepancies within the $m / z$ range $132-152$ is available in Supplementary Material. These differences are based on (i) the non-detection of one given species by one of the two MS technique or (ii) the detection of two different species, at a same nominal $\mathrm{m} / \mathrm{z}$. In this case, the detection of two distinct species leads to two different attributions. To illustrate this, we can focus on the nominal $m / z 132$ where two different species are detected: an ion at $m / z$ 132.0679 is detected in the LAb-CosmOrbitrap mass spectrum, when the LDI-FTICR mass spectrum presents an ion at $m / z$ 132.080789. These two $m / z$ ratios are distinguishable thanks to the mass resolution of the two MS techniques considered. They lead to the attribution of two molecular formulae, respectively $\mathrm{C}_{8} \mathrm{H}_{8} \mathrm{~N}_{2}{ }^{+}$and $\mathrm{C}_{9} \mathrm{H}_{10} \mathrm{~N}^{+}$. The first case (non-detection of a species by one of the two techniques) is more complex as it reveals that some information are sometimes missed by one technique. In the LAb-CosmOrbitrap mass spectrum, this is mostly caused by the low signal to noise ratio, having some peaks under the limit of detection. This is observable in the shorter $m / z$ range 139 to 142 , where peaks are too close to the noise level to be considered as peaks and are consequently not attributed. In the LDI-FTICR mass spectrum, the signal to noise ratio induced by the sum of 500 consecutives FID is very high, allowing the detection of low abundance ions. In addition, there is a strong difference about the energy applied on the sample, inducing two laser regimes different between both MS techniques: ablation for LAb-CosmOrbitrap and desorption for LDI-FTICR. Fragmentation is thus stronger in the LAb-CosmOrbitrap mass spectrum. Some fragment ions, detected in the LAb-CosmOrbitrap mass spectrum are possibly not formed with the LDI-FTICR technique and thus not observable in the mass spectrum.

This article is protected by copyright. All rights reserved. 


\subsection{Revealing low masses with the LAb-CosmOrbitrap}

One of the most useful tool in order to visualize ions distribution in a complex organic mixture mass spectrum is the mass defect versus exact mass diagram (MDVEM). This diagram represents the mass defect (experimental mass - nominal mass) of the detected compounds as a function of their experimental $\mathrm{m} / \mathrm{z}$ (Kendrick, 1963; Murray Kermit K. et al., 2013; Sleno, 2012). Each dot in the diagram represents the most intense $m / z$ value observed in the mass spectrum, at a given nominal mass.

A first visual distinction is made between compounds presenting a positive mass defect against those presenting a negative mass defect. Dots with a positive mass defect are highly dominated by organic compounds. Indeed, elements mainly composing organic compounds such as hydrogen and nitrogen have positive mass defects (respectively +0.0078 and $+0.0031 \mathrm{u}$, for $\mathrm{H}$ and $\mathrm{N}$ ). As tholins are synthesized using a gas mixture of $\mathrm{N}_{2}$ and $\mathrm{CH}_{4}$, their constituting molecules are composed of carbon, hydrogen and nitrogen, leading to positive mass defects regarding the formed compounds. They are observed on the Figure 4. On this diagram, red dots correspond to the LDI-FTICR ions and black circles to the LAb-CosmOrbitrap ones.

Thanks to the LAb-CosmOrbitrap instrumental configuration, including the sample-holder technique used, cluster ions between positive ions of the metallic sample-holder (here, ${ }^{115} \mathrm{In}^{+}$) and the neutral organic sample are observed in the mass spectra (Selliez et al., 2019). Formation mechanisms of these cluster ions are similar to those of non-covalent bonds, as referenced in Bhardwaj and Hanley, 2014; Carrasco et al., 2016 and Le Roy et al., 2015. MDvEM diagrams derived from the LAb-CosmOrbitrap mass spectra show thus a contribution with a negative mass defect coming from the detection of the indium positive ion. This element is indeed characterized by a large negative mass defect of -0.0962 $u$. As a reminder, the indium peak is observed in the LAb-CosmOrbitrap mass spectrum because it composes the metallic surface of the sample-holder. As the indium peak in the mass spectrum allows a useful calibration point for the whole mass spectrum, the indium dot in the MDvEM diagram marks the location where cluster ions [Organics $+\operatorname{In}]^{+}$should be observed. Indeed, the main asset of this MDVEM diagram is to reveal some specific trend lines, dots alignments or dots grouping, giving information about the possible polymers constituting a polymeric pattern but also clusters formed with a common element such as indium.

In the Figure 4, we observe this specific contribution with a negative mass defect, only for the CosmOrbitrap data (black circles). Indeed, due to the ablation ionization source employed, elements coming from the sample and the sample-holder are produced and detected. Dots composing this contribution are related to cluster ions including one positive ion of the main isotope of indium $\left({ }^{115} \mid \mathrm{n}^{+}\right)$. In addition to the indium positive ion, neutral organic compounds are identified such as HCN. Indeed,

This article is protected by copyright. All rights reserved. 
we observe at $m / z 141.9139$ the cluster assumed to be $[\mathrm{In}+\mathrm{HCN}]^{+}$. As we know the positive ion of indium to be present, we can remove its $m / z$ contribution: $141.9139-114.9033=27.0106$ leading to the neutral HCN value (i.e. 27.0109). Using this method, the following compounds have been identified: $\mathrm{HCN}, \mathrm{CH}_{2} \mathrm{~N}_{2}, \mathrm{CH}_{5} \mathrm{~N}_{3}, \mathrm{C}_{2} \mathrm{HN}_{3}, \mathrm{C}_{2} \mathrm{H}_{4} \mathrm{~N}_{4}, \mathrm{C}_{3} \mathrm{H}_{6} \mathrm{~N}_{4}$ and $\mathrm{C}_{4} \mathrm{H}_{6} \mathrm{~N}_{4}$. We note that such compounds are indirectly identified in their neutral form with indium clusters and also observed in their protonated and positive ion form, at lower masses. Cluster ions are thus indirectly indicative of organic compounds composing tholins. They allow the preservation of neutral organics. All these seven molecules provide a strong contribution of nitrogen elements in tholins and draw a consistent picture of the molecular growth from the light $\mathrm{HCN}$ molecule to the first N-PAH structures. The detection of HCN is important: it confirms the polymeric pattern suspected in tholins by Gautier et al., 2014 and Pernot et al., 2010 from a statistical analysis of the molecules formulae inferred from the high resolution mass spectra at higher $m / z . \mathrm{CH}_{2} \mathrm{~N}_{2}$ has previously been observed in tholins and identified as diazirine (cyclic isomer) after soft thermal desorption followed by VUV photoionization (Cunha de Miranda et al., 2016). The $\mathrm{CH}_{5} \mathrm{~N}_{3}$ species is identified as guanidine, already referenced in the study of Pernot et al., 2010. $\mathrm{C}_{2} \mathrm{HN}_{3}$ is consistent with dicyanamide (NC-NH-CN). This molecule has been previously observed as deprotonated $\left(\mathrm{C}_{2} \mathrm{~N}_{3}{ }^{-}\right.$at $\left.\mathrm{m} / \mathrm{z} 66\right)$ in the context of Titan's laboratory experiments: it appeared as a main fragment ion after MS/MS analysis of tholins ions in Carrasco et al., 2009 and as a major negative ion in the plasma discharge producing the tholins (Dubois et al., 2019). $\mathrm{C}_{2} \mathrm{H}_{4} \mathrm{~N}_{4}$ has two major isomers: the linear cyanoguanidine $\mathrm{HN}=\mathrm{C}\left(\mathrm{NH}_{2}\right)-\mathrm{NH}-\mathrm{CN}$, or the cyclic aminotriazole $\mathrm{NH}_{2}-\mathrm{C}_{2} \mathrm{~N}_{3} \mathrm{H}_{2}$. The triazole cycle is aromatic and might be thermodynamically favored in the plasma discharge producing tholins. It might be a first clue towards larger $\mathrm{N}$-heterocyclic polyaromatic hydrocarbons (N-PAH). $\mathrm{C}_{3} \mathrm{H}_{6} \mathrm{~N}_{4}$ has also several isomers, among them the possible methyl-aminotriazole, corresponding to the aminotriazole with an addition of a methyl group $\mathrm{CH}_{3}$. The $\mathrm{C}_{4} \mathrm{H}_{6} \mathrm{~N}_{4}$ presence could be explained by the addition of $\mathrm{C}_{2} \mathrm{H}_{2}$ on $\mathrm{C}_{2} \mathrm{H}_{4} \mathrm{~N}_{4}$, possibly leading to the formation of a second adjacent cycle. Others species detected are informative on the chemical composition of tholins material and still consistent with the presence of nitrogen-rich compounds. Looking for the protonated positive ions related to these compounds at low masses, we note that three of them are among the most intense peaks observed: $\left[\mathrm{CH}_{2} \mathrm{~N}_{2}+\mathrm{H}\right]^{+}$at $m / 243.0290 ;\left[\mathrm{CH}_{5} \mathrm{~N}_{3}+\mathrm{H}\right]^{+}$at $m / z 60.0556$ and $\left[\mathrm{C}_{2} \mathrm{H}_{4} \mathrm{~N}_{4}+\mathrm{H}\right]^{+}$at $m / z 85.0507$.

These direct and indirect observations of such organic compounds demonstrate analysis possibilities with the LAb-CosmOrbitrap instrumental configuration. Organic species detected at $m / z<100$ are consistent with cluster ions observed at $m / z>150$.

This article is protected by copyright. All rights reserved. 


\section{Conclusion and perspectives}

Mass spectra of a complex mixture (e.g. Titan's tholins) have been obtained for the first time with a homemade space-designed Orbitrap instrument (LAb-CosmOrbitrap). A comparison of results has been made with those obtained with a LDI-FTICR instrument, on the same sample. The two instrumental set-ups allow the study of the bulk tholins sample, giving a relevant comparative study.

First of all, both set-ups were able to reveal the complexity of the sample. As expected, higher dynamic range and resolution were observed in the FTICR mass spectrum due to the use of a commercial instrument allowing ions accumulation and long transient duration. Nevertheless, the $m / z$ range 100 200 allows, in both techniques, to recover the shape of a polymeric pattern. Looking at a same nominal mass, the main ions were detected and similarly attributed thanks to the high-enough mass resolving power. A few differences were observed, coming from the non-detection of a specific ion by one of the two techniques. This is well-explained by significant differences between the two set-ups, mostly about the transient accumulation and the laser regime.

In the LAb-CosmOrbitrap mass spectrum, cluster ions were also observed. They are composed by positive ion(s) coming from the metallic sample-holder and neutral organic compounds. Not detected in commercial MS techniques using softer ionization processes such as LDI-FTICR, cluster ions are indirect detections leading to the study of neutral organics composing the Titan's tholins. Chemical compounds identified point out the presence of nitrogen-rich species. They confirm hypotheses suggested by previous studies, for instance the role played by the HCN polymer in the construction of the polymeric pattern specific to the Titan's tholins.

With only one single laser shot and a short transient duration of less than one second, these results validate the capabilities of CosmOrbitrap to push forward the understanding of organic species in complex mixture encountered in space. The speed acquisition of a whole high resolution mass spectrum is a main asset of this instrumental configuration considering space missions with these specific limits. Other scenarios can be thought to improve the sensitivity of the data, such as using a higher number of laser shots and ions accumulation. A lower laser energy applied would allow a reduction of the tholins fragmentation and thus a possible detection of higher $m / z$ species. These assumptions have to be checked in the laboratory in order to determine how the best results can be obtained before being implemented on a space configuration.

In addition to the validation of our results by a benchtop laboratory technique, we can compare them with those obtained using space mass spectrometers and more specifically with the quadrupole mass spectrometers INMS and Huygens GC-MS, from the Cassini-Huygens mission, which studied in situ Titan's atmospheric composition. These instruments were only able to study a reduced $m / z$ range,

This article is protected by copyright. All rights reserved. 
respectively from $m / z 1$ to 99 (INMS) and $m / z 2$ to 141 (GC-MS) and at low resolution (m/ $/ \mathrm{m}$ of 100 at $m / z 100$ for both instruments). In our study, we were able to analyze tholins over the $m / z$ range 20 to about 200 . Our $m / z$ range is thus more informative than these two instruments. Moreover, the LAb-CosmOrbitrap mass range is initially more extended. The laboratory prototype is able to cover a $\mathrm{m} / \mathrm{z}$ range from 8 to few thousands. The space configuration in development and based on the LAbCosmOrbitrap aims at covering a $\mathrm{m} / \mathrm{z}$ range from 1 to 2,000 never reached neither by INMS nor the GC-MS. And this would be done with a mass resolving power higher of several magnitude order than the INMS and GCMS, as it can reach few hundreds of thousands until $\mathrm{m} / \mathrm{z} 136$ and few tens of thousands at $m / z 431$ for the Lab-CosmOrbitrap (Selliez et al., 2019).

To resume our study, we show in this work the relevance of a laser CosmOrbitrap instrument to provide a deep chemical analysis of a complex organic material. A laser CosmOrbitrap is the simplest instrumental configuration though for space. It provides an unprecedented mass-resolution allowing elemental identification of complex organic matter. A further issue to go deeper in the analysis will be to solve isomers and provide structural identification, as preliminary work by Gautier et al. 2016 demonstrated the need for with such complex samples using laboratory LC-Orbitrap. More complex configurations of the CosmOrbitrap could be proposed in that context, and the one that seems most suitable for this new challenge is the trapped ion mobility spectrometry (TIMS) (Castellanos et al., 2014; Tose et al., 2018). This technique, located before the mass spectrometer, allows to estimate the number of isomers present in a mixture. It allows, thanks to the retention of ions in a small electric field and their diffusion according to their collision with the gas flowing through pumping, to separate the isomers according to their size and charge. Its utility has recently been proven for the analysis of laboratory tholins and has allowed to show the isomeric diversity present in this complex environment (Rüger et al., 2019).

This article is protected by copyright. All rights reserved. 


\section{Acknowledgments}

L.S. thanks the Centre National d'Etudes Spatiales (CNES), the French space agency, and the Région Centre-Val-de-Loire for the funding of her PhD.

B.C. thanks CNES for the funding of his internship.

N.C. thanks the European Research Council (ERC) for funding via the ERC Primitive Chemistry project (grant agreement No. 636829.).

Financial support from the National Fourier transform ion cyclotron resonance network (FR 3624 CNRS) for conducting the research is also gratefully acknowledged.

This work was supported at Chimie Organique Bioorganique Réactivité Analyse (COBRA) laboratory by the European Regional Development Fund (ERDF) N³1708, the Région Normandie, and the Laboratoire d'Excellence (LabEx) Synthèse Organique (SynOrg) (ANR-11-LABX-0029).

\section{References}

Arevalo Jr, R., Selliez, L., Briois, C., Carrasco, N., Thirkell, L., Cherville, B., Colin, F., Gaubicher, B., Farcy, B., Li, X., Makarov, A., 2018. An Orbitrap-based laser desorption/ablation mass spectrometer designed for spaceflight. Rapid Commun. Mass Spectrom. 32, 1875-1886. https://doi.org/10.1002/rcm.8244

Balsiger, H., Altwegg, K., Bochsler, P., Eberhardt, P., Fischer, J., Graf, S., Jäckel, A., Kopp, E., Langer, U., Mildner, M., Müller, J., Riesen, T., Rubin, M., Scherer, S., Wurz, P., Wüthrich, S., Arijs, E., Delanoye, S., Keyser, J.D., Neefs, E., Nevejans, D., Rème, H., Aoustin, C., Mazelle, C., Médale, J.-L., Sauvaud, J.A., Berthelier, J.-J., Bertaux, J.-L., Duvet, L., Illiano, J.-M., Fuselier, S.A., Ghielmetti, A.G., Magoncelli, T., Shelley, E.G., Korth, A., Heerlein, K., Lauche, H., Livi, S., Loose, A., Mall, U., Wilken, B., Gliem, F., Fiethe, B., Gombosi, T.I., Block, B., Carignan, G.R., Fisk, L.A., Waite, J.H., Young, D.T., Wollnik, H., 2007. Rosina - Rosetta Orbiter Spectrometer for lon and Neutral Analysis. Space Sci. Rev. 128, 745-801. https://doi.org/10.1007/s11214-006-8335-3

Barrère, C., Hubert-Roux, M., Lange, C.M., Rejaibi, M., Kebir, N., Désilles, N., Lecamp, L., Burel, F., Loutelier-Bourhis, C., 2012. Solvent-based and solvent-free characterization of low solubility and low molecular weight polyamides by mass spectrometry: a complementary approach. Rapid Commun. Mass Spectrom. 26, 1347-1354. https://doi.org/10.1002/rcm.6231

Berry, J.L., Ugelow, M.S., Tolbert, M.A., Browne, E.C., 2019. Chemical Composition of GasPhase Positive Ions during Laboratory Simulations of Titan's Haze Formation. ACS Earth Space Chem. 3, 202-211. https://doi.org/10.1021/acsearthspacechem.8b00139

Bhardwaj, C., Hanley, L., 2014. Ion sources for mass spectrometric identification and imaging of molecular species. Nat. Prod. Rep. 31, 756-767. https://doi.org/10.1039/C3NP70094A

Briois, C., Thissen, R., Thirkell, L., Aradj, K., Bouabdellah, A., Boukrara, A., Carrasco, N., Chalumeau, G., Chapelon, O., Colin, F., Coll, P., Cottin, H., Engrand, C., Grand, N., Lebreton, J.-P., Orthous-Daunay, F.-R., Pennanech, C., Szopa, C., Vuitton, V., Zapf, P., Makarov, A., 2016. Orbitrap mass analyser for in situ characterisation of planetary 
environments: Performance evaluation of a laboratory prototype. Planet. Space Sci. 131, 33-45. https://doi.org/10.1016/j.pss.2016.06.012

Carrasco, N., Jomard, F., Vigneron, J., Etcheberry, A., Cernogora, G., 2016a. Laboratory analogues simulating Titan's atmospheric aerosols: Compared chemical compositions of grains and thin films. Planet. Space Sci. 128, 52-57. https://doi.org/10.1016/j.pss.2016.05.006

Carrasco, N., Jomard, F., Vigneron, J., Etcheberry, A., Cernogora, G., 2016b. Laboratory analogues simulating Titan's atmospheric aerosols: Compared chemical compositions of grains and thin films. Planet. Space Sci. 128, 52-57. https://doi.org/10.1016/j.pss.2016.05.006

Carrasco, N., Schmitz-Afonso, I., Bonnet, J.-Y., Quirico, E., Thissen, R., Dutuit, O., Bagag, A., Laprévote, O., Buch, A., Giulani, A., Adandé, G., Ouni, F., Hadamcik, E., Szopa, C., Cernogora, G., 2009. Chemical Characterization of Titan's Tholins: Solubility, Morphology and Molecular Structure Revisited. J. Phys. Chem. A 113, 11195-11203. https://doi.org/10.1021/jp904735q

Castellanos, A., Benigni, P., Hernandez, D.R., DeBord, J.D., Ridgeway, M.E., Park, M.A., Fernandez-Lima, F., 2014. Fast Screening of Polycyclic Aromatic Hydrocarbons using Trapped Ion Mobility Spectrometry - Mass Spectrometry. Anal. Methods Adv. Methods Appl. 6, 9328-9332. https://doi.org/10.1039/C4AY01655F

Coll, P., Coscia, D., Smith, N., Gazeau, M.-C., Ramírez, S.I., Cernogora, G., Israël, G., Raulin, F., 1999. Experimental laboratory simulation of Titan's atmosphere: aerosols and gas phase. Planet. Space Sci. 47, 1331-1340. https://doi.org/10.1016/S00320633(99)00054-9

Cunha de Miranda, B., Garcia, G.A., Gaie-Levrel, F., Mahjoub, A., Gautier, T., Fleury, B., Nahon, L., Pernot, P., Carrasco, N., 2016. Molecular Isomer Identification of Titan's Tholins Organic Aerosols by Photoelectron/Photoion Coincidence Spectroscopy Coupled to VUV Synchrotron Radiation. J. Phys. Chem. A 120, 6529-6540. https://doi.org/10.1021/acs.jpca.6b03346

Denisov, E., Damoc, E., Lange, O., Makarov, A., 2012. Orbitrap mass spectrometry with resolving powers above 1,000,000. Eugene N Nikolaev 65th Birthd. Honor Issue 325327, 80-85. https://doi.org/10.1016/j.ijms.2012.06.009

Dubois, D., Carrasco, N., Bourgalais, J., Vettier, L., Desai, R.T., Wellbrock, A., Coates, A.J., 2019. Nitrogen-containing Anions and Tholin Growth in Titan's lonosphere: Implications for Cassini CAPS-ELS Observations. Astrophys. J. 872, L31. https://doi.org/10.3847/2041-8213/ab05e5

Fleury, B., Carrasco, N., Gautier, T., Mahjoub, A., He, J., Szopa, C., Hadamcik, E., Buch, A., Cernogora, G., 2014. Influence of CO on Titan atmospheric reactivity. Icarus 238, 221-229. https://doi.org/10.1016/j.icarus.2014.05.027

Gautier, T., Carrasco, N., Schmitz-Afonso, I., Touboul, D., Szopa, C., Buch, A., Pernot, P., 2014. Nitrogen incorporation in Titan's tholins inferred by High Resolution Orbitrap Mass Spectrometry and Gas-Chromatography-Mass Spectrometry. https://doi.org/10.1016/j.epsl.2014.07.011

Gautier, T., Sebree, J.A., Li, X., Pinnick, V.T., Grubisic, A., Loeffler, M.J., Getty, S.A., Trainer, M.G., Brinckerhoff, W.B., 2017. Influence of trace aromatics on the chemical growth mechanisms of Titan aerosol analogues. Planet. Space Sci. 140, 27-34.

https://doi.org/10.1016/j.pss.2017.03.012

This article is protected by copyright. All rights reserved. 
Hadamcik, E., Renard, J.-B., Alcouffe, G., Cernogora, G., Levasseur-Regourd, A.C., Szopa, C., 2009. Laboratory light-scattering measurements with Titan's aerosols analogues produced by a dusty plasma. Surf. Atmospheres Outer Planets Their Satell. Ring Syst. Part V 57, 1631-1641. https://doi.org/10.1016/j.pss.2009.06.013

Hörst, S.M., Yoon, Y.H., Ugelow, M.S., Parker, A.H., Li, R., de Gouw, J.A., Tolbert, M.A., 2018. Laboratory investigations of Titan haze formation: In situ measurement of gas and particle composition. Icarus 301, 136-151. https://doi.org/10.1016/j.icarus.2017.09.039

Kendrick, Edward., 1963. A Mass Scale Based on $\mathrm{CH} 2=14.0000$ for High Resolution Mass Spectrometry of Organic Compounds. Anal. Chem. 35, 2146-2154. https://doi.org/10.1021/ac60206a048

Le Roy, L., Altwegg, K., Balsiger, H., Berthelier, J.-J., Bieler, A., Briois, C., Calmonte, U., Combi, M.R., De Keyser, J., Dhooghe, F., Fiethe, B., Fuselier, S.A., Gasc, S., Gombosi, T.I., Hässig, M., Jäckel, A., Rubin, M., Tzou, C.-Y., 2015. Inventory of the volatiles on comet 67P/Churyumov-Gerasimenko from Rosetta/ROSINA. A\&A 583. https://doi.org/10.1051/0004-6361/201526450

Le Vot, C., Afonso, C., Beaugrand, C., Tabet, J.-C., 2011. Implementation of a Penning ionization source on a FTICR instrument with ion funnel optics. https://doi.org/10.1016/j.ijms.2010.10.005

Maillard, J., Carrasco, N., Schmitz-Afonso, I., Gautier, T., Afonso, C., 2018. Comparison of soluble and insoluble organic matter in analogues of Titan's aerosols. Earth Planet. Sci. Lett. 495, 185-191. https://doi.org/10.1016/j.epsl.2018.05.014

Makarov, A., 2000. Electrostatic Axially Harmonic Orbital Trapping: A High-Performance Technique of Mass Analysis. Anal. Chem. 72, 1156-1162. https://doi.org/10.1021/ac991131p

Murray Kermit K., Boyd Robert K., Eberlin Marcos N., Langley G. John, Li Liang, Naito Yasuhide, 2013. Definitions of terms relating to mass spectrometry (IUPAC Recommendations 2013). Pure Appl. Chem. 85, 1515. https://doi.org/10.1351/PACREC-06-04-06

Niemann, H.B., Atreya, S.K., Demick, J.E., Gautier, D., Haberman, J.A., Harpold, D.N., Kasprzak, W.T., Lunine, J.I., Owen, T.C., Raulin, F., 2010. Composition of Titan's lower atmosphere and simple surface volatiles as measured by the Cassini-Huygens probe gas chromatograph mass spectrometer experiment. J. Geophys. Res. Planets 115. https://doi.org/10.1029/2010JE003659

Nikolaev, E.N., Boldin, I.A., Jertz, R., Baykut, G., 2011. Initial Experimental Characterization of a New Ultra-High Resolution FTICR Cell with Dynamic Harmonization. J. Am. Soc. Mass Spectrom. 22, 1125-1133. https://doi.org/10.1007/s13361-011-0125-9

O'Connor, P.B., Mirgorodskaya, E., Costello, C.E., 2002. High pressure matrix-assisted laser desorption/ionization Fourier transform mass spectrometry for minimization of ganglioside fragmentation. J. Am. Soc. Mass Spectrom. 13, 402-407. https://doi.org/10.1016/S1044-0305(02)00351-3

Page, J.S., Tolmachev, A.V., Tang, K., Smith, R.D., 2006. Theoretical and Experimental Evaluation of the Low $\mathrm{m} / \mathrm{z}$ Transmission of an Electrodynamic Ion Funnel. J. Am. Soc. Mass Spectrom. 17, 586-592. https://doi.org/10.1016/j.jasms.2005.12.013

Pernot, P., Carrasco, N., Thissen, R., Schmitz-Afonso, I., 2010. Tholinomics-Chemical Analysis of Nitrogen-Rich Polymers. Anal. Chem. 82, 1371-1380. https://doi.org/10.1021/ac902458q 
Perry, R.H., Cooks, R.G., Noll, R.J., 2008. Orbitrap mass spectrometry: Instrumentation, ion motion and applications. Mass Spectrom. Rev. 27, 661-699. https://doi.org/10.1002/mas.20186

Rüger, C.P., Maillard, J., Le Maître, J., Ridgeway, M., Thompson, C.J., Schmitz-Afonso, I., Gautier, T., Carrasco, N., Park, M.A., Giusti, P., Afonso, C., 2019. Structural Study of Analogues of Titan's Haze by Trapped Ion Mobility Coupled with a Fourier Transform Ion Cyclotron Mass Spectrometer. J. Am. Soc. Mass Spectrom. 30, 1169-1173. https://doi.org/10.1007/s13361-019-02205-7

Sciamma-O'Brien, E., Carrasco, N., Szopa, C., Buch, A., Cernogora, G., 2010. Titan's atmosphere: An optimal gas mixture for aerosol production? Icarus 209, 704-714. https://doi.org/10.1016/j.icarus.2010.04.009

Sciamma-O'Brien, E., Ricketts, C.L., Salama, F., 2014. The Titan Haze Simulation experiment on COSmIC: Probing Titan's atmospheric chemistry at low temperature. Icarus 243, 325-336. https://doi.org/10.1016/j.icarus.2014.08.004

Sciamma-O'Brien, E., Upton, K.T., Salama, F., 2017. The Titan Haze Simulation (THS) experiment on COSmIC. Part II. Ex-situ analysis of aerosols produced at low temperature. Icarus 289, 214-226. https://doi.org/10.1016/j.icarus.2017.02.004

Selliez, L., Briois, C., Carrasco, N., Thirkell, L., Thissen, R., Ito, M., Orthous-Daunay, F.-R., Chalumeau, G., Colin, F., Cottin, H., Engrand, C., Flandinet, L., Fray, N., Gaubicher, B., Grand, N., Lebreton, J.-P., Makarov, A., Ruocco, S., Szopa, C., Vuitton, V., Zapf, P., 2019. Identification of organic molecules with a laboratory prototype based on the Laser Ablation-CosmOrbitrap. Planet. Space Sci. https://doi.org/10.1016/j.pss.2019.03.003

Sleno, L., 2012. The use of mass defect in modern mass spectrometry. J. Mass Spectrom. 47, 226-236. https://doi.org/10.1002/jms.2953

Smith, D.F., Podgorski, D.C., Rodgers, R.P., Blakney, G.T., Hendrickson, C.L., 2018. 21 Tesla FT-ICR Mass Spectrometer for Ultrahigh-Resolution Analysis of Complex Organic Mixtures. Anal. Chem. 90, 2041-2047. https://doi.org/10.1021/acs.analchem.7b04159

Somogyi, A., Oh, C.-H., Smith, M.A., Lunine, J.I., 2005. Organic Environments on Saturn's Moon, Titan: Simulating Chemical Reactions and Analyzing Products by FT-ICR and Ion-Trap Mass Spectrometry. J. Am. Soc. Mass Spectrom. 16, 850-859. https://doi.org/10.1016/j.jasms.2005.01.027

Szopa, C., Cernogora, G., Boufendi, L., Correia, J.J., Coll, P., 2006. PAMPRE: A dusty plasma experiment for Titan's tholins production and study. Planet. Space Sci. 54, 394-404. https://doi.org/10.1016/j.pss.2005.12.012

Tose, L.V., Benigni, P., Leyva, D., Sundberg, A., Ramírez, C.E., Ridgeway, M.E., Park, M.A., Romão, W., Jaffé, R., Fernandez-Lima, F., 2018. Coupling trapped ion mobility spectrometry to mass spectrometry: trapped ion mobility spectrometry-time-offlight mass spectrometry versus trapped ion mobility spectrometry-Fourier transform ion cyclotron resonance mass spectrometry. Rapid Commun. Mass Spectrom. 32, 1287-1295. https://doi.org/10.1002/rcm.8165 
Table 1 : Specifications of both instrumental set-up: LAb-CosmOrbitrap and LDI-FTICR. The chart is separated in three main sections: sample, ionization and mass analysis.

\begin{tabular}{|c|c|c|c|}
\hline 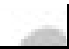 & Instrumental set-up & LAb-CosmOrbitrap & LDI-FTICR \\
\hline \multirow{3}{*}{$\begin{array}{l}\frac{0}{0} \\
\sum_{\tilde{N}}^{0} \\
\text { N }\end{array}$} & Sample & \multicolumn{2}{|c|}{ solid tholins powder (PAMPRE, $5 \% \mathrm{CH}_{4}$ ) } \\
\hline & Sample-holder & Homemade circular indium sample-holder & Commercial stainless steel MALDI plate \\
\hline & Estimated thickness & \multicolumn{2}{|c|}{$<100 \mu \mathrm{m}$} \\
\hline \multirow{11}{*}{ 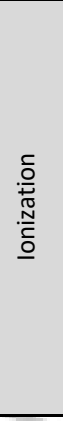 } & Laser type & $\mathrm{Nd}-\mathrm{YAG} 4 \omega$ & $N d-Y A G 3 \omega$ \\
\hline & Wavelength & $266 \mathrm{~nm}$ & $355 \mathrm{~nm}$ \\
\hline & Laser regime & Ablation/desorption & Desorption \\
\hline & Laser pulse duration & $4 \mathrm{~ns}$ & $3 \mathrm{~ns}$ \\
\hline & Laser power & $42 \mathrm{~kW}$ & $24 \mathrm{~kW}$ \\
\hline & Used output & $171 \mu$ & $0.43 \mu$ \\
\hline & Spot size (on sample) & $18,558 \mu \mathrm{m}^{2}$ & $706 \mu \mathrm{m}^{2}$ \\
\hline & Fluence & $2.60 \mathrm{~J} / \mathrm{cm}^{2}$ & $0.06 \mathrm{~J} / \mathrm{cm}^{2}$ \\
\hline & Number laser shot & 1 & $40 * 500$ \\
\hline & Repetition rate & N/A & $1,000 \mathrm{~Hz}$ \\
\hline & $\begin{array}{c}\text { Pressure inside mass analyzer } \\
\text { chamber } \\
\end{array}$ & $10^{-9} \mathrm{mbar}$ & $3 * 10^{-10} \mathrm{mbar}$ \\
\hline \multirow{5}{*}{ 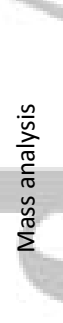 } & Mass analyzer & Orbitrap $^{\mathrm{TM}}$ cell (D30) & Paracell $^{\mathrm{TM}}$ cell \\
\hline & Transient duration & $838 \mathrm{~ms}$ & $2.2 \mathrm{~s}$ \\
\hline & Apodization window & Hann & Half-sine \\
\hline & $\begin{array}{l}\text { Mass resolving power } \\
\text { FWHM at } m / z 430\end{array}$ & Up to 70,000 & 600,000 \\
\hline & Mass range & $\mathrm{m} / \mathrm{z} 1$ to 2,000 (for the space configuration) & $\mathrm{m} / \mathrm{z} 98$ to 1,200 \\
\hline
\end{tabular}


Table 2 : Similar detections in the $\mathrm{m} / \mathrm{z}$ range 133 to 152, between LAb-CosmOrbitrap and LDI-FTICR mass spectra. Theoretical $\mathrm{m} / \mathrm{z}$ and molecular formula are given in the two first columns. Each molecular formula is correlated to the measured $\mathrm{m} / \mathrm{z}$ of the corresponding peak, within the precision of the technique, and its mass accuracy (in ppm) for both techniques. The $m / z$ value is given within the precision of the instrumental configuration: respectively 4 and 6 digits for the LAb-CosmOrbitrap and the LDI-FTICR set-ups. In this $\mathrm{m} / \mathrm{z}$ range, 26 molecular formulae have been attributed from the LAb-CosmOrbitrap mass spectrum, 38 from the LDI-FTICR mass spectrum. Between both mass spectra, 21 ions are in common and referenced in the Table. Only common ions are indicated in this table. The global table starting at $\mathrm{m} / \mathrm{z} 132$, including similarities and discrepancies, is given in Supplementary Material.

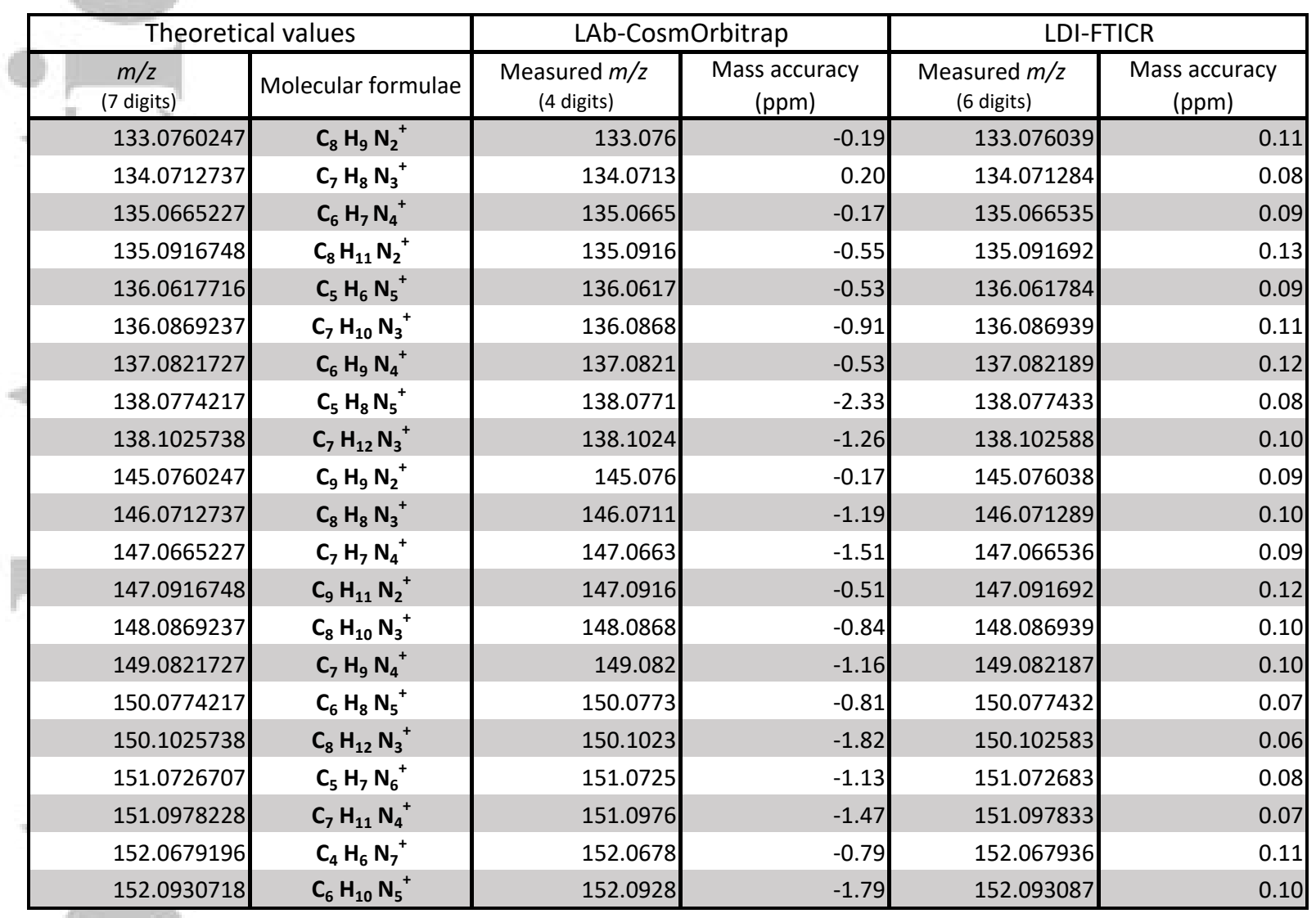

This article is protected by copyright. All rights reserved. 

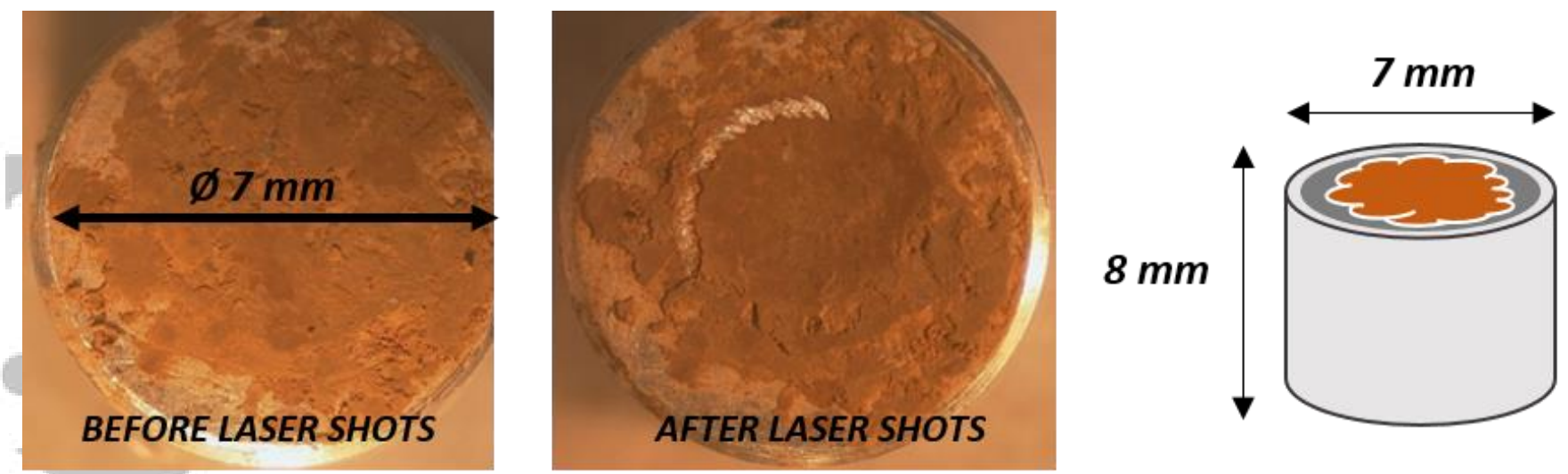

Figure 1 : Pictures of the Titan's tholins powder pressed onto the indium sample-holder of the LAb-CosmOrbitrap before laser shot (left) and after laser shots (middle). On the middle picture, laser shots are visible on the brown tholins powder, demonstrating the ablation of the sample. The scheme (right) illustrates dimensions of the sample-holder (8 $\mathrm{mm}$ height and $7 \mathrm{~mm}$ diameter).

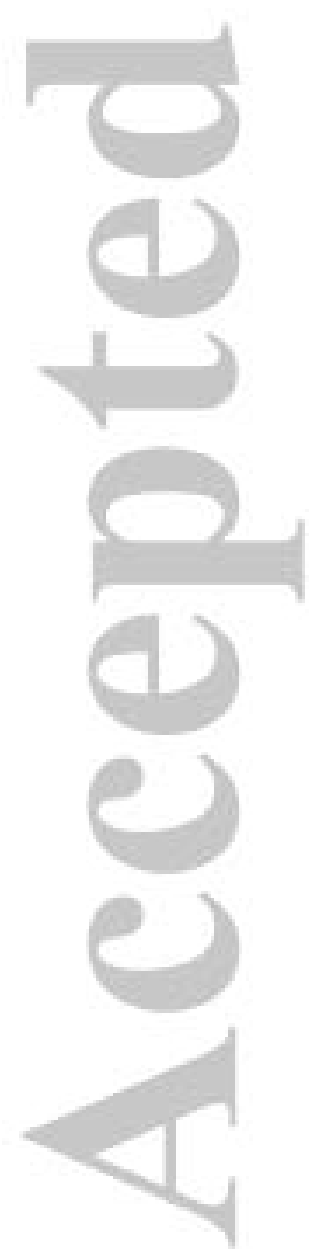

This article is protected by copyright. All rights reserved. 


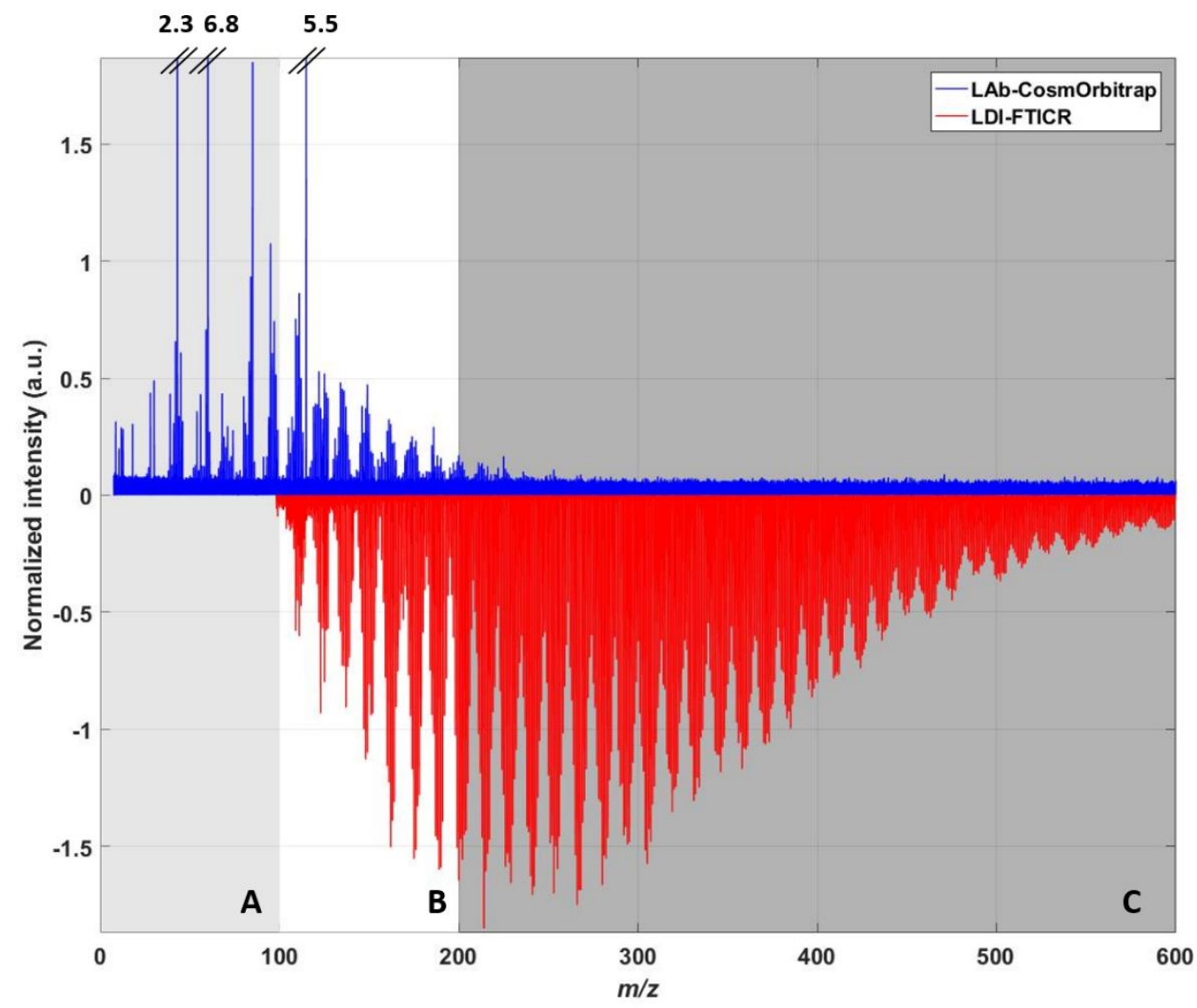

Figure 2 : Comparison of positive ions mass spectra (1) LAb-CosmOrbitrap, in blue, top panel and (2) LDI-FTICR, in red, lower panel in reverse scale. Intensities of three peaks (m/z 43.0290; 60.0556 and 114.9033) in the LAb-CosmOrbitrap mass spectrum are out of the window and thus reported at the top the window. Mass spectra are separated in three distinct zones named $A, B$ and $C$. Each zone is detailed in a specific result section. 


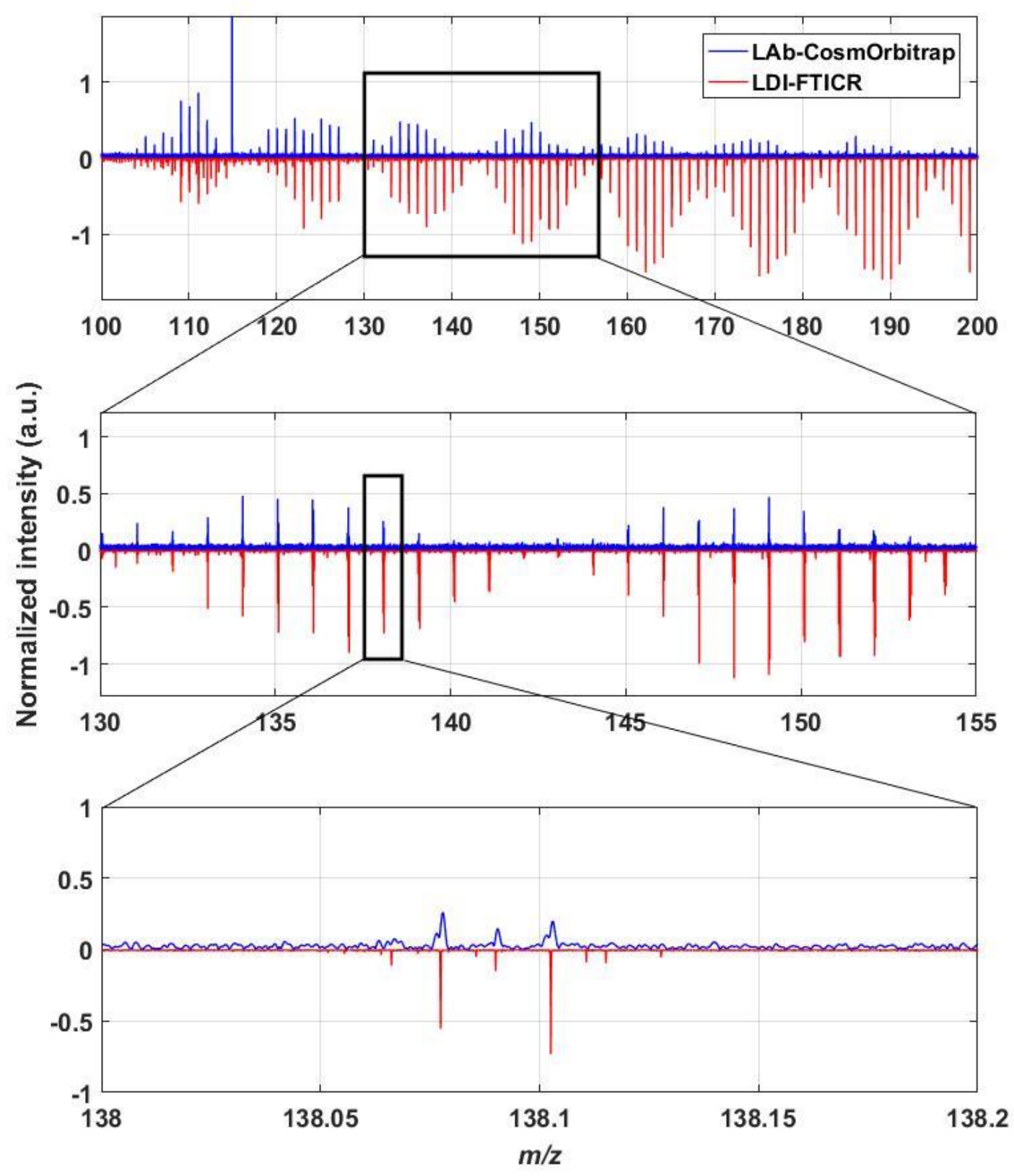

Figure 3 : Focus on three distinct zones in the LAb-CosmOrbitrap and LDI-FTICR mass spectra, as presented in Figure 1. The first window (top) shows $\mathrm{m} / \mathrm{z}$ from 100 to 200. A black box indicates the next window (middle) from $\mathrm{m} / \mathrm{z} 130$ to 155. Again, another black box indicates the last window (bottom) from $\mathrm{m} / \mathrm{z} 138$ to 138.2. As a reminder from the Figure 1, the LAbCosmOrbitrap mass spectrum is the blue top panel and the LDI-FTICR mass spectrum the red low panel in reverse scale. 

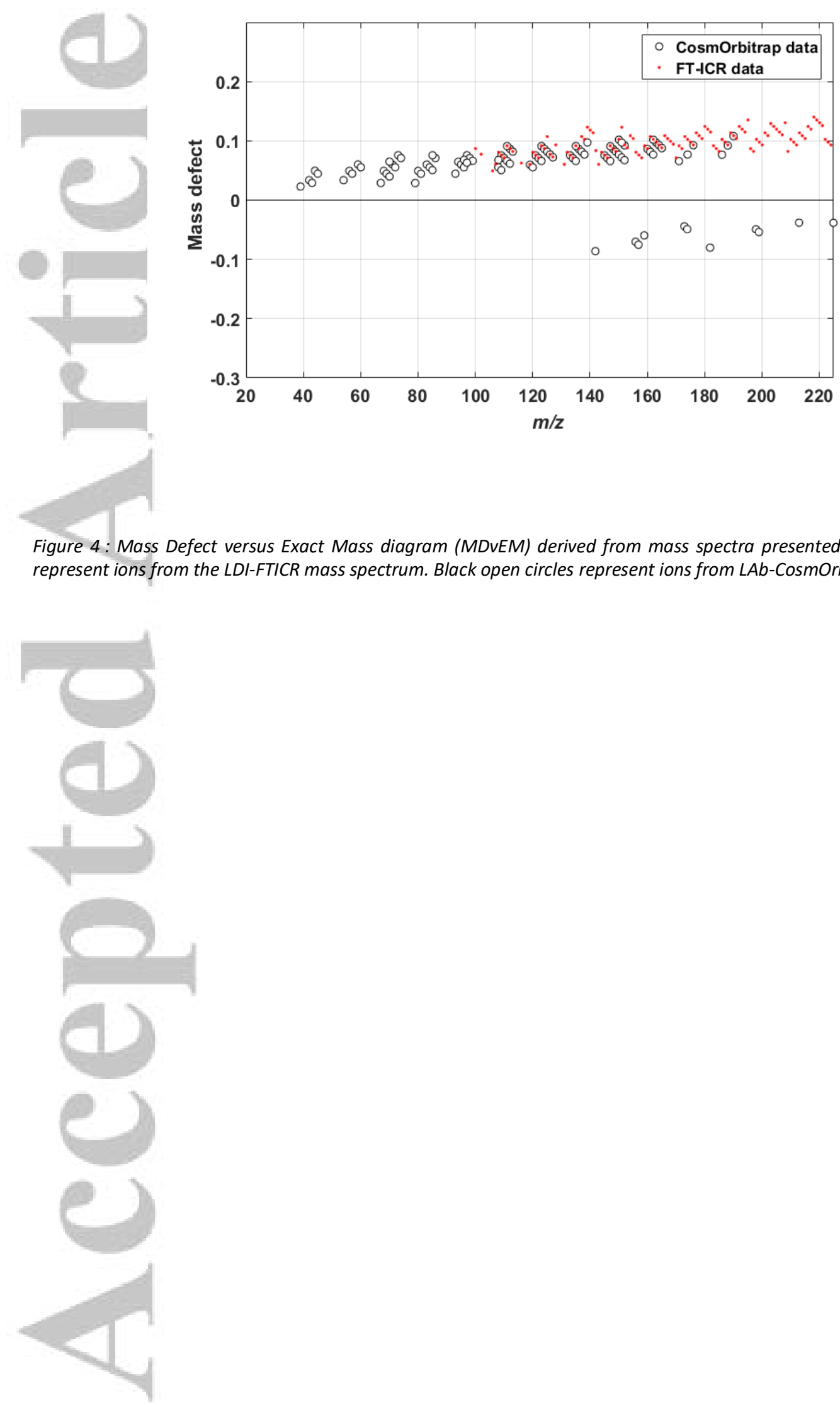

Figure 4: Mass Defect versus Exact Mass diagram (MDVEM) derived from mass spectra presented in Figure 1. Red dots represent ions from the LDI-FTICR mass spectrum. Black open circles represent ions from LAb-CosmOrbitrap mass spectrum. 